\title{
Role of CEA and CA19-9 in Predicting Metastasis, Operability and Resectability in Patients of Carcinoma Gall Bladder
}

Dr. Ankit Panwar ${ }^{1}$, Dr. Puneet Mahajan ${ }^{2}$, Dr. Saurabh Galodha ${ }^{3}$, Dr. Samant Negi ${ }^{4}$, Dr. Ashish Thakur ${ }^{1 *}$

${ }^{1}$ M.O.General Surgery, Civil Hospital Rajgarh, Hospital Rd, Rajgarh, Himachal Pradesh 173101, India

${ }^{2}$ Professor, Department of General Surgery, IGMC Shimla, Ridge Sanjauli Rd, Lakkar Bazar, Shimla, Himachal Pradesh 171001, India

${ }^{3}$ Assistant Professor, Department of Gastro Surgery, AIIMS Delhi, Sri Aurobindo Marg, Ansari Nagar, Ansari Nagar East, New Delhi, Delhi 110029, India

${ }^{4}$ M.O.General Surgery, Civil Hospital Rohru, Rohru, Himachal Pradesh 171207, India

Article History

Received: 12.10 .2020

Accepted: 28.10 .2020

Published: 04.11.2020

Journal homepage: https://www.easpublisher.com/easjms

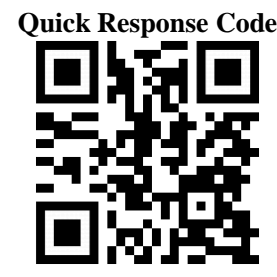

Abstract: Introduction: Gall bladder carcinoma was first described in $17^{\text {th }}$ century, Incidence of gall stones increased over time and so is the incidence of carcinoma gall bladder. Still tumor remains characterized by an unfavourable prognosis due to silent progression of the clinical course and limited knowledge of its aetiology and poor scientific capability for epidemiological forecasting. The incidence of GBC varies in different parts of the world. Overall incidence ranges from $0.11 / 100000$ to $10.6 / 100000$ in different cancer registries worldwide [1]. Our study is an attempt to establish relationship between CA19-9, CEA with metastasis, operability and resectability. Methods: Study type is prospective cohort study. It was carried out among newly diagnosed, intraoperative and referred cases of carcinoma gall bladder at IGMC Shimla. All newly diagnosed, intraoperative and referred cases of carcinoma gallbladder were recruited in the study. The total duration of study was of one year. Result: Female sex in their sixties are most commonly involved. Gall stones are associated with $56 \%$ of the patients. In CECT abdomen most common finding is of metastatic disease. Adenocarcinoma is most common HPE finding. CEA and CA19-9 both show direct relation with metastasis and in operability and inverse relation with resectability however results were not statistically significant. Conclusion: Gall bladder carcinoma incidence is increasing with time but measures to tackle it not evolving at the desired speed. CEA and CA19-9 showed some promising results but still a larger study needed to establish relation between them and the factors mentioned above. Primary prevention will arrive once high risk environmental toxins and genetic abnormalities are clearly identified and further studies should be dedicated for its early diagnosis and treatment.

Keywords: Gall bladder carcinoma, CEA, CA19-9, IGMC Shimla.

Copyright (C) 2020 The Author(s): This is an open-access article distributed under the terms of the Creative Commons Attribution 4.0 International License (CC BY-NC 4.0) which permits unrestricted use, distribution, and reproduction in any medium for non-commercial use provided the original author and source are credited.

\section{INTRODUCTION}

Gall bladder carcinoma was first described in $17^{\text {th }}$ century, Incidence of gall stones increased over time and so is the incidence of carcinoma gall bladder. Still tumor remains characterized by an unfavourable prognosis due to silent progression of the clinical course and limited knowledge of its aetiology and poor scientific capability for epidemiological forecasting. The incidence of Gall Bladder carcinoma varies in different parts of the world. Overall incidence ranges from $0.11 / 100000$ to $10.6 / 100000$ in different cancer registries worldwide [1]. The prognosis is poor, only about a 32 percent 5 year survival rate for lesions confined to the gallbladder mucosa and a 10 percent one-year survival rate for more advanced stages ${ }^{2}$. The incidence in northern Indian cities is much higher than the southern Indian cities. In Delhi and Bhopal the incidence is 7 and 1.6 per 100,000 for male and 10.6 and 4 per 100,000 for females [1]. The residents of
Indo-Gangetic belt particularly females of northern India (21.5/100000) and South Karachi Pakistan $(13.8 / 100000)$ have been reported as one of the highest affected regions [3]. Although Gallbladder cancer is more common in females, still in some countries like Korea, Iceland and Costa Rica, higher mortality rate has been reported for males as compare to females [4]. The development of gallbladder cancer has been linked to various genetic and environmental factors. Chronic infection of gallbladder or/and environmental exposure to specific chemicals, heavy metals, and even many dietary factors, have been found to be associated with GBC formation. The dramatic association of GBC with female gender and certain geographical regions (mostly developing countries) has been proposed to be influenced by various female hormones, cholesterol cycling and salmonella infections in existing literature $[5,6]$. There has been many studies going on to establish relations between tumor markers and prognosis, metastasis and operability. Our study is also 
an attempt to establish relationship between CA19-9, CEA with metastasis, operability and resectability.

\section{METHODS}

This study was a prospective cohort study and was carried out among newly diagnosed, intraoperative and referred cases of carcinoma gall bladder at IGMC Shimla. All newly diagnosed, intraoperative and referred cases of carcinoma gallbladder were recruited in the study. The total duration of study was of one year. Patients included were having

1. Thickening of gall bladder wall on U.S.G abdomen.

2. Incidental carcinoma gall bladder.

3. Intraoperative diagnosed carcinoma gall bladder.

4. Consented to participate in study

All previously treated patients, all those who did not give written consents and patients who were mentally not sound enough to give consent or interview were excluded from the study. All those patients coming to IGMC Shimla general surgery department fulfilling the inclusion criteria for first 9 months were included in the study. Detailed history was taken and clinical examination of patients was done. Blood investigations namely complete haemogram, renal function tests, liver function tests, serum electrolyte levels, blood glucose level, PT/INR, serum total protein and albumin levels, blood CEA and CA19-9 levels were done. Radiological evaluation namely chest X-ray, ultrasound abdomen and contrast enhanced CT scan and MRCP as per requirement was done. Patients were treated according to cancer stage, TNM classification and staging was used to classify the disease and treatment modality.

\section{RESULTS}

The mean age of participants was $61.0 \pm 12.8$. $56 \%$ of patients are in age group of $60-80$. In present study out of 45 patient $36(80 \%)$ were females and $9(20 \%)$ were males.

Out of 45 patients $25(55.56 \%)$ patients had ultrasonographically proven cholelithiasis.

Out of 45 patients of carcinoma gall bladder $37(82.22 \%)$ were presented with pain Right upper quadrant of abdomen as chief complaint abdomen followed by jaundice (55.56\%), Dyspepsia (53.33\%), anorexia (62.22\%) and weight loss $(53.33 \%)$.

21 patients $(46.67 \%)$ had normal serum CEA levels, 20(44.44\%) patients had moderately raised CEA levels and 4(8.89\%) had extensively raised CEA levels.

\begin{tabular}{|l|l|l|}
\hline CEA & FREQUENCY & PERCENT \\
\hline NORMAL $(<\mathbf{2 . 5 n g / m l )}$ & 21 & $46.67 \%$ \\
\hline MODERATELY RAISED $(\mathbf{2 . 5}$ to 500ng/ml) & 20 & $44.44 \%$ \\
\hline EXENTENSIVELY RAISED $(\boldsymbol{\mathbf { 5 5 0 n }} / \mathbf{m l})$ & 4 & $8.89 \%$ \\
\hline TOTAL & 45 & $100.00 \%$ \\
\hline
\end{tabular}

25 patients $(55.56 \%)$ patients had normal serum CA 19-9 levels, 12(26.67\%) patients had moderately raised CA $19-9$ levels and $8(17.78 \%)$ had extensively raised CA 19-9 levels.

\begin{tabular}{|l|l|l|}
\hline CA 19 -9 & FREQUENCY & PERCENT \\
\hline NORMAL (<37U/ml) & 25 & $55.56 \%$ \\
\hline MODERATELY RAISED (>90U/ml) & 12 & $26.67 \%$ \\
\hline EXTENSIVELY RAISED $(>450 U / m l)$ & 8 & $17.78 \%$ \\
\hline TOTAL & 45 & $100.00 \%$ \\
\hline
\end{tabular}

9 patients $(20 \%)$ patients had non metastatic disease in which fat plains were well maintained, $13(28.88 \%)$ patients had non metastatic disease in which disease was locally advanced and in 23(51.12\%) patients disease was metastatic on CECT abdomen with pelvis.

\begin{tabular}{|l|l|l|}
\hline CECT ABDOMEN & FREQUENCY & PERCENT \\
\hline NON METASTATIC (FAT PLANES MAINTAINED) & 9 & $20.00 \%$ \\
\hline NON METASTATIC (LOCALLY ADVANCED) & 13 & $28.88 \%$ \\
\hline METASTATIC & 23 & $51.12 \%$ \\
\hline TOTAL & 45 & $100.00 \%$ \\
\hline
\end{tabular}

28 patients $(62.22 \%)$ patients had adenocarcinoma on HPE and in $17(37.78 \%)$ tissue diagnosis was not present.
In this study CEA levels were normal in 21 cases out of which 12 were inoperable, 6 were resectable and 3 were unresectable. CEA levels were moderately raised in 20 cases out of which 9 were inoperable, 6 were resectable and 5 were unresectable. 
The levels were extensively raised in 4 cases out of which 2 were inoperable, 1 was resectable and 1 was unresectable. This difference was not statistically significant.

\begin{tabular}{|c|c|c|c|c|c|}
\hline & \multicolumn{5}{|c|}{ TREATMENT PROFILE } \\
\hline CEA & INOPERABLE & RESECTABLE & UNRESECTABLE & TOTAL & P VALUE \\
\hline NORMAL & $12(57.14 \%)$ & $6(28.57 \%)$ & $3(14.29 \%)$ & $21(100 \%)$ & 0.91 \\
\hline MODERATELY RAISED & $9(45 \%)$ & $6(30 \%)$ & $5(25 \%)$ & $20(100 \%)$ & \\
\hline EXTENSIVELY RAISED & $2(50 \%)$ & $1(25 \%)$ & $1(25 \%)$ & $4(100 \%)$ & \\
\hline TOTAL & $23(51.11 \%)$ & $13(28.89 \%)$ & $9(20 \%)$ & $45(100 \%)$ & \\
\hline
\end{tabular}

In this study CA 19-9 levels were normal in 25 cases out of which 13 were inoperable, 7 were resectable and 5 were unresectable. CA19-9 levels were moderately raised in 12 cases out of which 5 were inoperable, 5 were resectable and 2 were unresectable.
The levels were extensively raised in 8 cases out of which 5 were inoperable, 1 was resectable and 2 were unresectable. The difference was not stastically significant.

\begin{tabular}{|l|l|l|l|l|l|}
\hline & \multicolumn{2}{|l|}{ TREATMENT PROFILE } & \multicolumn{2}{l|}{} \\
\hline CA 19-9 & INOPERABLE & RESECTABLE & UNRESECTABLE & TOTAL & P-VALUE \\
\hline NORMAL & $13(52 \%)$ & $7(28 \%)$ & $5(20 \%)$ & $25(100 \%)$ & \\
\hline MODERATELY RAISED & $5(41.67 \%)$ & $5(41.67 \%)$ & $2(16.67 \%)$ & $12(100 \%)$ & \multirow{2}{*}{0.73} \\
\hline EXTENSIVELY RAISED & $5(62.5 \%)$ & $1(12.5 \%)$ & $2(25 \%)$ & $8(100 \%)$ & \\
\hline TOTAL & $23(51.11 \%)$ & $13(28.89 \%)$ & $9(20 \%)$ & $45(100 \%)$ & \\
\hline
\end{tabular}

\begin{tabular}{|l|l|l|}
\hline CA 19-9 & \multicolumn{1}{|c|}{ NO.OF PATIENTS } \\
\hline \multirow{2}{*}{ NORMAL } & $\begin{array}{l}\text { METASTASIS(ON CECT ABDOMEN } \\
\text { +PELVIS) }\end{array}$ & $15(33.33 \%)$ \\
\cline { 2 - 3 } & NO METASTASIS & $11(24.44 \%)$ \\
\hline $\begin{array}{l}\text { RAISED(moderately and extensively } \\
\text { raised) }\end{array}$ & METASTASIS & $14(31.11 \%)$ \\
\cline { 2 - 3 } & NO METASTASIS & $5(11.11 \%)$ \\
\hline
\end{tabular}

CA19-9 is normal in $24.4 \%$ patients in which CECT abdomen show no metastasis while in $33.33 \%$ patients with normal CA19-9 there is metastasis on CECT abdomen.
Also in $31.11 \%$ patients where CA19-9 is raised there is metastasis while in $11.11 \%$ patients there is raised CA19-9 but there is no metastasis.

\begin{tabular}{|l|l|l|}
\hline CEA & & NO. OF PATIENTS \\
\hline \multirow{2}{*}{ NORMAL } & $\begin{array}{l}\text { METASTASIS(ON CECT ABDOMEN } \\
\text { +PELVIS) }\end{array}$ & $13(28.88 \%)$ \\
\cline { 2 - 3 } & NO METASTASIS & $7(15.55 \%)$ \\
\hline \multirow{2}{*}{$\begin{array}{l}\text { RAISED (moderately and extensively } \\
\text { raised) }\end{array}$} & METASTASIS & $17(37.77 \%)$ \\
\cline { 2 - 3 } & NO METASTASIS & $8(17.77 \%)$ \\
\hline
\end{tabular}

CEA is normal in $15.55 \%$ patients in which CECT abdomen show no metastasis while in $28.88 \%$ patients with normal CEA there is metastasis on CECT abdomen.

Also in $37.77 \%$ patients where CEA is raised there is metastasis while in $17.77 \%$ patients there is raised CA19-9 but there is no metastasis.

\section{DISCUSSION}

In United States it is the sixth common gastrointestinal malignancy [9]. In our analysis of 45 patients, females outnumbered males and constituted $80 \%$ of total cases with a male to female ratio of 1:4.This finding was consistent with other studies where male to female ratio was in favor of females, however it was more than other studies with most series reporting a ratio of 1:3,1:2.5 $[7,8,10,11]$. However Liang [12] reported a male to female ratio of $1: 1$.Although women are two to six times more commonly affected by gall bladder cancer than men, the incidence steadily rises with age [13]. In the present study it was observed that most of the patients were from age group 61-80years followed by 41-60years this was in sharp contrast to the concept given by Kapoor S et al., [14] as maximum number of patients were in the age group 30-40 years. And in the present study age at diagnosis ranged from 33 to 80years which is consistent with the study done by Gulwani HV et al., [15]. The most common presenting symptom in our study was abdominal pain $(82.22 \%)$ followed by anorexia $(62.22 \%)$, dyspepsia $(53.33 \%)$, weight loss $(53.33 \%)$. This is consistent with results from other studies which have reported abdominal pain to be the most common presenting 
symptom. In our study, gall stones were seen in 25 cases $(55.56 \%$ of all the cases). Cholelithiasis is a well established risk factor for the development of gall bladder carcinoma [16] and gall stones were present in $74 \%-92 \%$ of affected patients. However in our study, gall stones were seen only in $55.56 \%$ of cases with carcinoma gall bladder. This is a significant finding in an area where gall stones have a high prevelance [17].

CT is better than ultrasound in detecting the gall bladder lesion and helpful to know the status of liver involvement but of little value in knowing the nodal status. Consistent with our study. Wang et al., [18] reported that bile Retinol binding protein 4 was correlated with body mass index positively. But it is in contrast to our study as in our study maximum number of patients fall in normal BMI category. In the study conducted by Shukla et al., [19] 335 GBC patients were analysed, They reported that when the serum CA19-9 level is $>90 \mathrm{U} / \mathrm{mL}, 94 \%$ of the patientis were unresectable, and when the level rose to $>450 \mathrm{U} / \mathrm{mL}$, $100 \%$ of those patients were unresectable. The scoring system, inspired by child standards, was widely used to assess patients with liver disease under consideration for surgical resection, but in our study it is not statistically significant. It may be due to small size of our study. A study by Singh et al., reported that median overall survival (OS) for unresectable GBC patients was 11.3 months [20]. Median OS for unresectable GBC patients who were treated with best supportive care, fluorouracil and folinic acid, and modified gemcitabine and oxaliplatin were 4.5, 4.6, and 9.5 months, respectively. In conclusion, this study identified a combination of an elevated CEA and CA199 was independent predictor of a poor prognosis in GBC patients undergoing resection.

\section{CONCLUSION}

Gall bladder carcinoma has a highly variable prevalence. Unfortunately the usual presentation at an advanced stage because of non specific symptoms is associated with high mortality. Surgery represents the only possible cure provided patient is diagnosed early. Improved imaging modalities as well as accurate diagnostic tumor markers will probably help outcome. Improved outcome greatly depend upon the recognition of major risk factors, accurate tumor staging and meticulous surgical intervention. Primary prevention will arrive once high risk environmental toxins and genetic abnormalities are clearly identified. CEA and CA19-9 showed some promising results but still a larger study needed to establish relation between them and the factors mentioned above. Primary prevention will arrive once high risk environmental toxins and genetic abnormalities are clearly identified and further studies should be dedicated for its early diagnosis and treatment.

\section{REFERENCES}

1. National Cancer Registry Programme: first all India Report 2001-2002.summary of specific sites. New Delhi: Indian Council of Medical Research, 2004; 225-227.

2. Lazcano-Ponce, E. C., Miquel, J. F., Muñoz, N., Herrero, R., Ferrecio, C., Wistuba, I. I., ... \& Nervi, F. (2001). Epidemiology and molecular pathology of gallbladder cancer. $C A$ : a cancer journal for clinicians, 51(6), 349-364.

3. Randi, G., Franceschi, S., \& La Vecchia, C. (2006). Gallbladder cancer worldwide: geographical distribution and risk factors. International journal of cancer, 118(7), 1591-1602.

4. Hariharan, D., Saied, A., \& Kocher, H. M. (2008). Analysis of mortality rates for gallbladder cancer across the world. $H P B, 10(5), 327-331$.

5. Pilgrim, C. H., Groeschl, R. T., Christians, K. K., \& Gamblin, T. C. (2013). Modern perspectives on factors predisposing to the development of gallbladder cancer. $H P B, 15(11), 839-844$.

6. Iyer, P., Barreto, S. G., Sahoo, B., Chandrani, P., Ramadwar, M. R., Shrikhande, S. V., \& Dutt, A. (2016). Non-typhoidal Salmonella DNA traces in gallbladder cancer. Infectious agents and cancer, 11(1), 1-4.

7. Pandey, M., Pathak, A. K., Gautam, A., Aryya, N. C., \& Shukla, V. K. (2001). Carcinoma of the Gallbladder. Digestive diseases and sciences, 46(6), 1145-1151.

8. Giang, T. H., Ngoc, T. T., \& Hassell, L. A. (2012). Carcinoma involving the gallbladder: a retrospective review of 23 cases-pitfalls in diagnosis of gallbladder carcinoma. Diagnostic Pathology, 7(1), 10.

9. Greenlee, R. T., Murray, T., Bolden, S., \& Wingo, P. A. (2000). Cancer statistics, 2000. CA: a cancer journal for clinicians, 50(1), 7-33.

10. Shukla, V. K., Khandelwal, C., Roy, S. K., \& Vaidya, M. P. (1985). Primary carcinoma of the gall bladder: A review of a 16-year period at the university hospital. Journal of surgical oncology, 28(1), 32-35.

11. Beltz, W. R., \& Condon, R. E. (1974). Primary carcinoma of the gallbladder. Annals of surgery, $180(2), 180$.

12. Liang, J. W., Dong, S. X., Zhou, Z. X., Tian, Y. T., Zhao, D. B., Wang, C. F., \& Ping, Z. H. A. O. (2008). Surgical management for carcinoma of the gallbladder: a single-institution experience in 25 years. Chinese medical journal, 121(19), 19001905.

13. Scott, T. E., Carroll, M., Cogliano, F. D., Smith, B. F., \& Lamorte, W. W. (1999). A case-control assessment of risk factors for gallbladder carcinoma. Digestive diseases and sciences, 44(8), 1619-1625.

14. Kapoor, S. (2014). An observational study to find out the frequency of Gall Bladder Cancer in 
patients of gall bladder disease. IOSRJDMS, 13(7), 1-5.

15. Gulwani, H. V., Gupta, S., \& Kaur, S. (2015). Incidental detection of carcinoma gall bladder in laparoscopic cholecystectomy specimens: a thirteen year study of 23 cases and literature review. Indian journal of surgical oncology, 6(1), 30-35.

16. Lowenfels, A. B., Lindström, C. G., Conway, M. J., \& Hastings, P. R. (1985). Gallstones and risk of gallbladder cancer. Journal of the national cancer institute, 75(1), 77-80.

17. Khuroo, M. S., Mahajan, R., Zargar, S. A., Javid, G., \& Sapru, S. (1989). Prevalence of biliary tract disease in India: a sonographic study in adult population in Kashmir. Gut, 30(2), 201-205.
18. Wang, W., \& Li, N. (2015). Correlation of retinol binding protein 4 with metabolic indexes of glucose and lipid, bile cholesterol saturation index. Zhong nan da xue xue bao. Yi xue ban= Journal of Central South University. Medical Sciences, 40(6), 657-665.

19. Shukla, P. J., Neve, R., Barreto, S. G., Hawaldar, R., Nadkarni, M. S., Mohandas, K. M., \& Shrikhande, S. V. (2008). A new scoring system for gallbladder cancer (aiding treatment algorithm): an analysis of 335 patients. Annals of surgical oncology, 15(11), 3132-3137.

20. Singh, S. K., Talwar, R., Kannan, N., Tyagi, A. K., Jaiswal, P., \& Kumar, A. (2015). Aggressive surgical approach for gallbladder cancer: a singlecenter experience from northern India. Journal of gastrointestinal cancer, 46(4), 399-407. 